\title{
Near-Death Prophecies of Disaster and the New Age: Are They True?
}

\author{
Alfred S. Alschuler, Ph.D., D.H.L., H.D.P. \\ Appalachian State University
}

ABSTRACT: Planetary visions of many near-death-experiences predicted a rise in disasters culminating in economic breakdown and the possibility of nuclear war in 1987-88, though the apocalypse could be postponed if human beings increased their love for God, each other, and the earth (the New Age Effect). I examined long-range data and found trend reversals in 1987-88: increases in religiosity, service, and United Nations peacekeeping efforts, and decreases in chlorofluorocarbon production, nuclear warhead stockpiles, arms exports, and interest in economic well-being. Long-range trend data also show rises in the number of weather disasters, fires, and accidents peaking in 1987-88 and then declining. The correlation of these diverse, predicted trends supports the hypothesized New Age Effect. Further research is suggested for testing the New Age Effect.

At the borderland between life and death, when consciousness seems to escape the body, it may also seem to transcend earthly laws and enter another world. Most people who have near-death experiences (NDEs) believe this; those who experience a planetary vision (PV) during their NDE are convinced they received knowledge of our global future (Audette, 1981; Grey, 1985; Ring, 1982, 1984, 1988). PVs often portrayed an apocalypse beginning in the early 1980s with an increasing number of earthquakes, volcanos, land mass changes, a pole shift, extreme weather conditions, and food shortages culminating around 1988 with famine, social disorder, economic collapse,

Alfred S. Alschuler, Ph.D., is Professor of Human Development and Psychological Counseling in the Reich College of Education at Appalachian State University in Boone, NC. Reprint requests should be addressed to Dr. Alschuler at Route 7, Box 132, Circle Drive, Boone, NC 28607. 
and the possibility of a nuclear war. These horrendous events were viewed as a necessary educational transition to the New Age.

Although the ultimate outcome is inevitable, according to these PVs, the timing and events of the transition are not. One NDEr reported that:

During my experience I . . was made to understand that nothing is absolutely fixed and that everything depends on how we choose to use our own free will, that even those events that are already predestined can be changed or modified by a change in our own way of relating to them. (Grey, 1985, p. 123)

Another NDEr said, "Unless people learn to get along and care about each other and care about other life on this planet, there will be no planet" (Ring, 1984, p. 206).

This is more than a warning against war and wasting our natural resources. PVs teach that there is a causal link between a collective loving consciousness and disasters that works both ways. First, disasters are a natural consequence of violating universal laws:

I was informed that mankind was breaking the laws of the universe, and as a result of this would suffer. . . Mankind, I was told, was being consumed by the cancers of arrogance, materialism, racism, chauvinism and separatist thinking. (Ring, 1984, p. 198)

Second, obeying the universal laws by changing our collective attitudes and actions will reduce disasters and postpone the apocalypse:

It [was] given to me that in 1988 , the world will be destroyed by earthquakes and volcanic eruptions, but if people will turn to God and honor Him, some of these things will be put off. (Ring, 1984, p. 206

Another NDEr reported that 1988 would "be the year everything would be wiped away if we didn't change" (Ring, 1984, p. 205).

I will refer to this hypothesized causal connection as the New Age Effect, since either disasters will educate us to be more loving, or being more loving will reduce disasters. Both are routes to the New Age of peace, universal love, and wise stewardship of the earth.

By 1988 the earth had not changed its axis, California and Florida were still part of the mainland, nuclear war had not happened, and worldwide economic collapse and social chaos had not occurred. Is there any evidence that human beings used their free will around 1987-88 to turn toward God and care more for each other and the 
planet? Is there any support for the New Age Effect? To answer these questions, I examined published long-range trend data for significant changes in planetary conditions around 1987-88.

\section{Method}

Long-term trend data on United States religiosity were taken from the Gallup Organization. They have asked a variety of questions to a stratified random sample of United States citizens since the 1950s (Gallup Poll News Service, 1994). Not every question, however, was asked every year; thus, trends are not available on the full array of questions they asked.

Trend data on caring for others were obtained from the University of California, Los Angeles's Cooperative Institutional Research Program (CIRP), which has conducted yearly national surveys of college freshmen for 25 years (Astin, Korn, and Riggs, 1993; Dey, Astin, Korn, and Riggs, 1992). While the attitudes of college students are not direct indicators of current national attitudes, they are plausible predictors of future adult values.

The Worldwatch Institute provides yearly data on nine aspects of the planet's health (Brown, 1994; Brown, et al., 1994). Their data are obtained from a variety of sources.

The United States Office of Foreign Disaster Assistance (OFDA) has been the definitive source of data on worldwide disasters since 1964, their inaugural year. OFDA defines disasters as follows (personal communication, 1994):

Earthquakes and volcanos are included if the number of people killed is at least six, or the total number killed and injured is 25 or more, or at least 1,000 people are affected, or damage is one million dollars or more . . .

Weather disasters (floods, storms, typhoons, landslides, heat and cold waves, etc.) are included if the number of people killed and injured totals at least 50 , or 1,000 or more are homeless or affected, ore damage is at least one million dollars ... .

Accidents (fires, plane crashes, train wrecks, the Chernobyl nuclear accident, the Bhopal chemical leak, etc.) are included if the number killed or injured is at least 100 , or damage is estimated at one million dollars or more. 
Several limitations in OFDA data should be considered when interpreting these trends. First, the numbers killed and affected are approximate. Therefore I included in this study only the number of disasters and not yearly sums of killed and affected individuals.

Second, over time several extraneous factors have increased the number of disasters included in the OFDA census. The dollar amount of damage is a function of inflation. Since the cost of disasters has increased, more disasters qualify now than did 30 years ago. There is greater population density in some marginal and high risk areas. Improved record keeping also may account for some increases. These factors not only contribute to increases over time, but also tend to make decreases less steep.

Third, the numbers of reported droughts and food shortages do not come from reliable sources. They reflect political and financial interests of countries requesting American aid, rather than the actual numbers affected, and may be massively over- or underestimated. For example, Emperor Haile Selassie denied the existence of a famine in Ethiopia, but his successor, Mengistu Haile Mariam, overestimated the numbers so that donated foodstuffs could feed his army and be converted into cash to support his war against Eritrea, Tigray, and the Wollo. Food shortages and related phenomena such as civil strife, population displacement, refugee flows, and droughts are interrelated, multiyear, and multicountry events. OFDA has not been consistent in reporting these either as one event or as multiple events, nor in the number of years the events are reported.

A fourth limitation is that OFDA has data only on countries outside the United States. The Federal Emergency Management Agency (FEMA) keeps data on American emergencies and disasters. FEMA deliberately does not define emergencies or disasters. Assistance is determined in each case based on severity, availability of federal funds, and political factors. FEMA does not report the number of disaster and emergency requests it has turned down, nor will FEMA officials comment on whether the definitions of disasters have changed over time (United States Federal Emergency Management Agency, personal communication, 1994). For these reasons the FEMA data are too confounded to provide meaningful trends. Thus, I included in this study disaster data from all countries except the United States.

To see the disaster trends more clearly, I have combined yearly data into graphs that show rolling three year totals: that is, the total for 1964-66, then the total for 1966-67, and so on. 


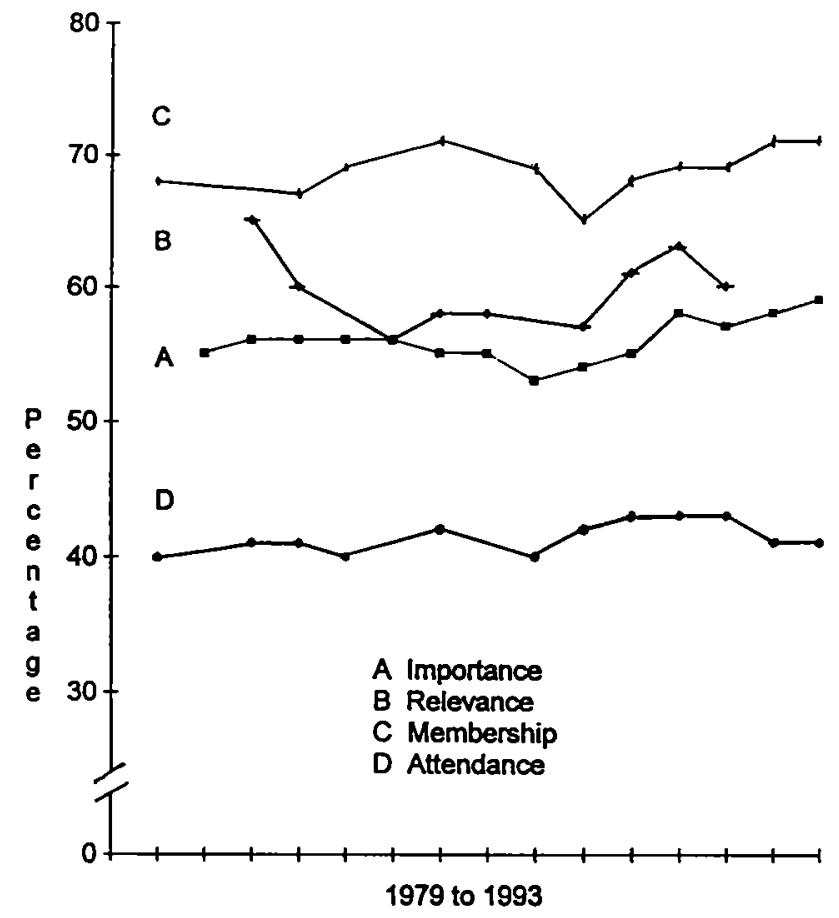

Figure 1. Trends in U. S. religiosity. From Gallup Poll News Service. (1994). Religious Trends. Princeton, NJ: Gallup Organization, pp. 1-5. Copyright 1994 by the Gallup Poll Organization. Adapted with permission.

\section{Results}

Did People Turn Toward God Around 1987-88?

Four of the Gallup Organization's questions about American religiosity were sufficiently germane and frequently asked to report in Figure 1. This graph shows the percentage of respondents who agreed with the following statements: $A=$ "Religion is very important in my life"; B = "Religion can answer all or more of today's problems"; C = "I am a member of a church or synagogues"; and D = "I went to church or synagogue within the last seven days."

With the exception of church or synagogue attendance, which remained stable within a 3 percent range for 15 years, the other three 


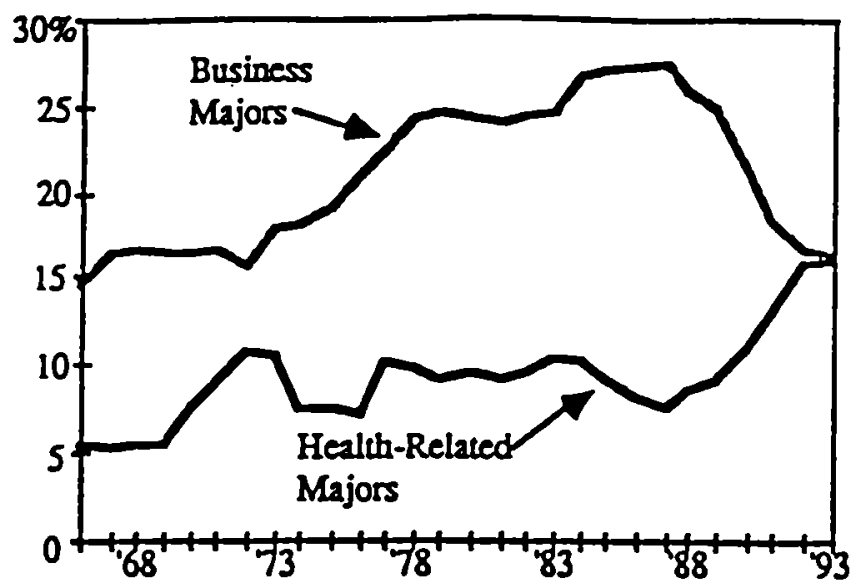

Figure 2. Changing freshman interest in business and health-related majors. From Cooperative Institutional Research Program. (1994). The American Freshman: National Norms For Fall 1993. Los Angeles, CA: UCLA Higher Education Research Institute, p. 2. Copyright by the CIRP of the Higher Education Research institute, UCLA Graduate School of Education. Used with permission of CIRP.

indices of religiosity hit a low in 1987 or 1988 and began to rise, as predicted. Given the stratified random sample of the American population, an increase of 6 percent represents up to 16 million American citizens.

Did People Begin Caring More for Each Other in 1987-88?

CIRP surveys show trends in freshmen "caring" and can be seen as predictions of future mature adult trends (Astin, Korn, and Riggs, 1993; Dey, Astin, Korn, and Riggs, 1992). Again, as seen in Figures 2, 3, and 4, 1987 was a turning point. Figure 2 shows that college students majoring in business began to decline, while health-related majors began to rise. Figure 3 shows a shift in freshmen's life goals: numbers of those seeking to "be well off financially" began to decline, while those seeking to "develop a meaningful philosophy of life" began to rise. Figure 4 shows that freshmen's "commitment to promoting racial understanding as a life goal" began to rise after 1987. 


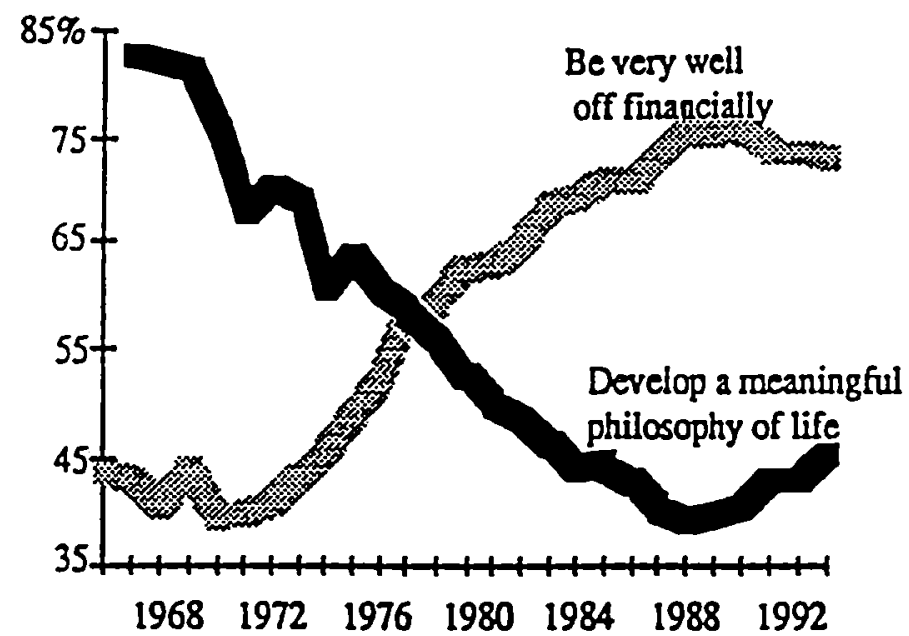

Figure 3. Freshman life goals. From Cooperative Institutional Research Program. (1993). The American Freshman: National Norms For Fall 1992. Los Angeles, CA: UCLA Higher Education Research Institute, p. 2. Copyright by the CIRP of the Higher Education Research Institute, UNCL Graduate School of Education. Used with permission of CIRP.

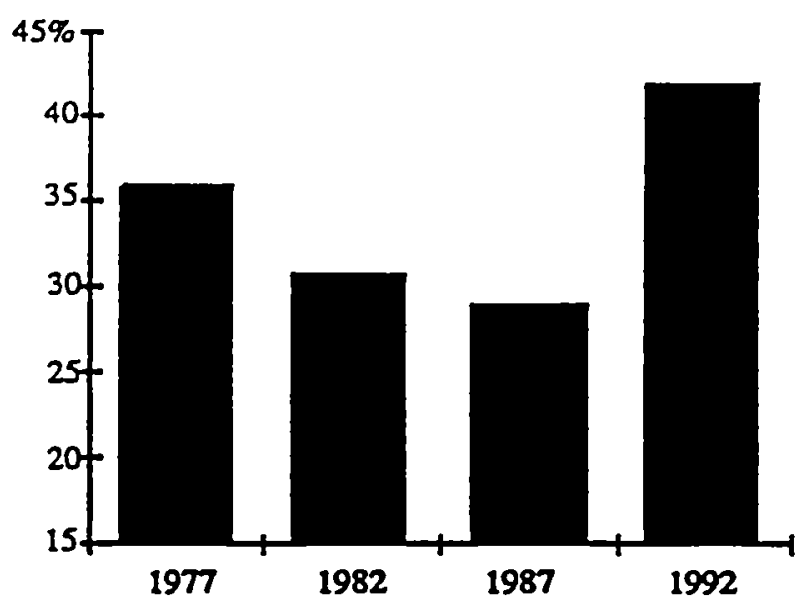

Figure 4. Commitment to promoting racial understanding as a life goal. From Cooperative Institutional Research Program. (1993). The American Freshman: National Norms For Fall 1992. Los Angeles, CA: UCLA Higher Education Research Institute, UCLA Graduate School of Education. Used with permission of CIRP. 


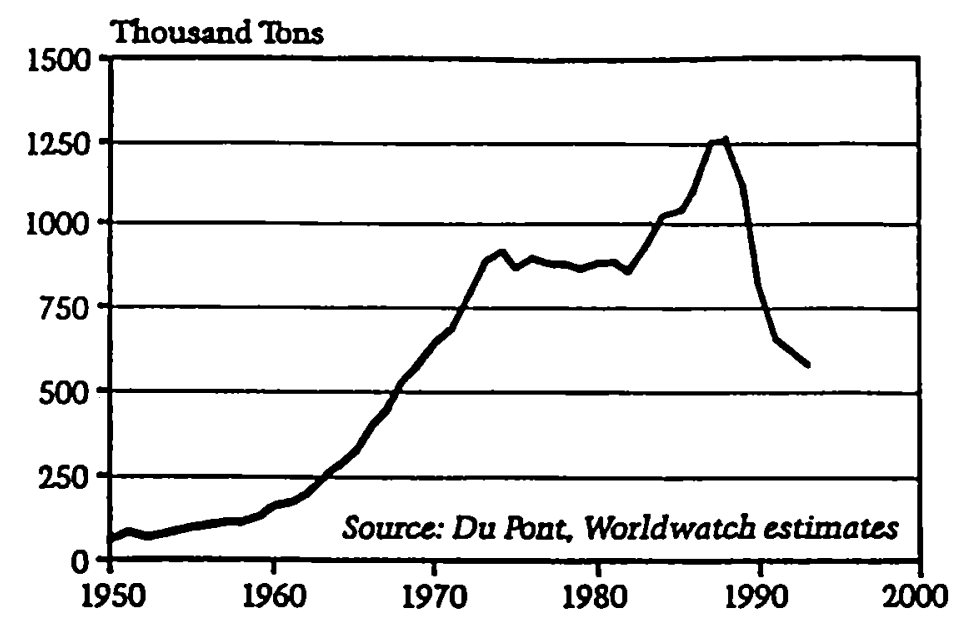

Figure 5. World production of chlorofluorocarbons, 1950-93. From Brown, L. R. (1994). Vital Signs: The Trends That Are Shaping Our Future. New York, NY: Norton, p. 65. Copyright 1994 by the Worldwatch Institute. Reprinted with permission.

Did People Begin to Take Better Care of the Planet Around 1987-88?

Data on the care of the earth are published each year by the Worldwatch Institute (Brown, 1994). Two of the most closely watched signs are the world production of chlorofluorocarbons (CFCs), and the number of nuclear warheads, since both pose apocalyptic threats to the world. Four related trends are presented in graphs 5, 6, 7, and 8 .

As seen in Figure 5, world CFC production peaked in 1987 and then dropped rapidly, beginning in 1988. Figure 6 shows that the number of worldwide nuclear warheads peaked in 1986 at 69,480 , and began dropping in 1987. By 1994 the total had decreased by 28 percent. Figure 7 shows that the export of conventional weapons peaked in 1984 and again in 1987, while a drop of 63 percent began in 1988. As seen in Figure 8, there was a rapid rise in the number of United National peacekeeping missions starting in 1988. These reflect significant formal international agreements and unprecedented collective action for peace beginning in the predicted years.

These clear breaks in long-range trends are in marked contrast to all but three of the remaining 35 vital signs-indicators such as 


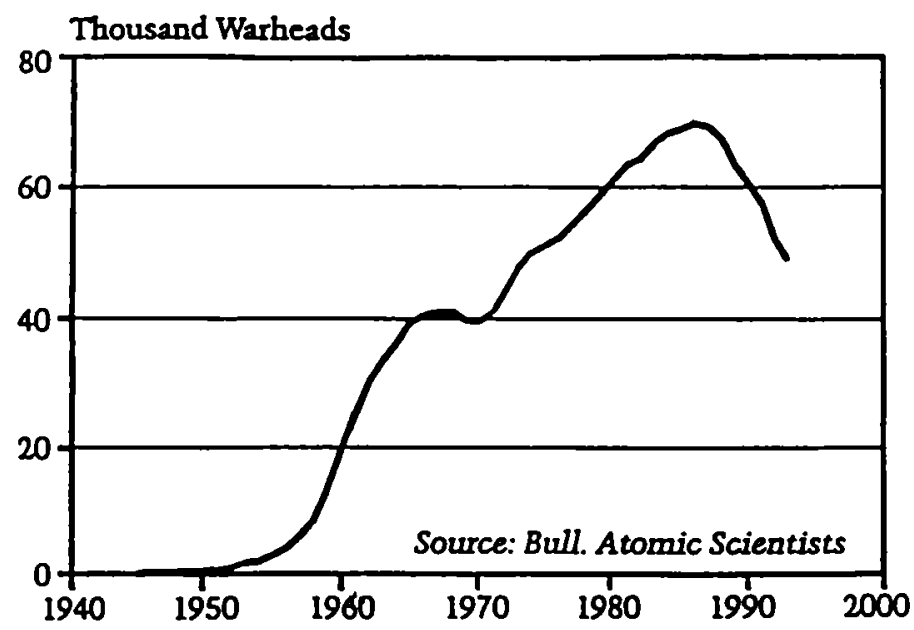

Figure 6. Global nuclear arsenal, 1945-93. From Norris, R. S., and Arkin, W. M. (1993, December). Estimated nuclear stockpiles 1945-93. Bulletin of the Atomic Scientists. Copyright 1993 by the Bulletin of the Atomic Scientists. Reprinted with permission.

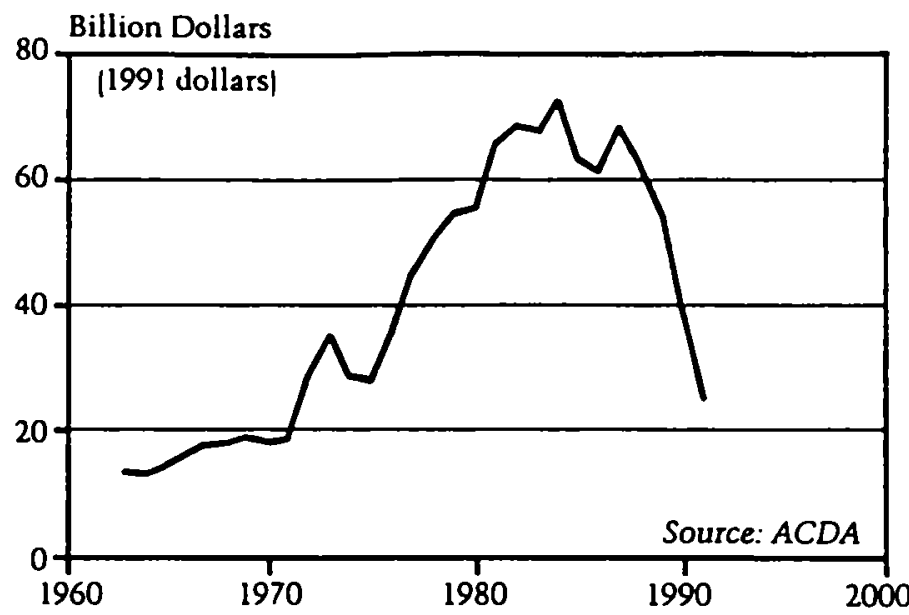

Figure 7. Exports of conventional weapons. From Brown, L. R. (1994). Vital Signs: The Trends That Are Shaping Our Future. New York, NY: Norton, p. 111. Copyright 1994 by the Worldwatch Institute. Reprinted with permission. 


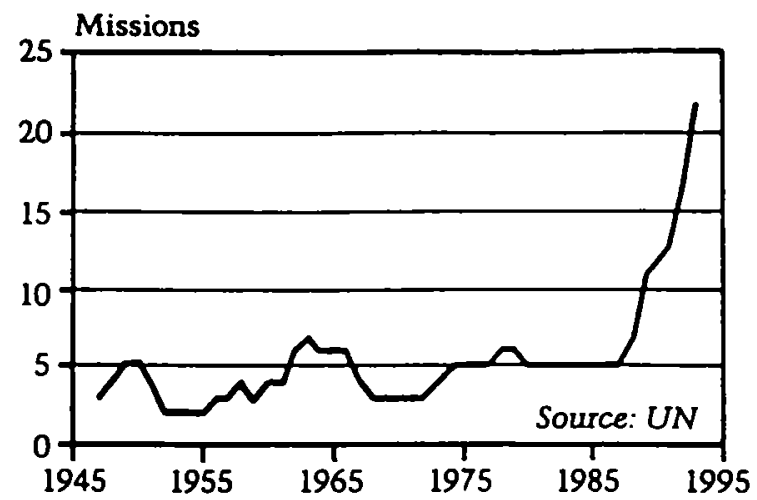

Figure 8. Number of peacekeeping missions per year, 1947-93. From Brown, L. R. (1994). Vital Signs: The Trends That Are Shaping Our Future. New York, NY: Norton, p. 113. Copyright 1994 by the Worldwatch Institute. Reprinted with permission.

world production of gain, corn, soybeans, meat, and fish catch; irrigation; production of oil and wind energy; global average temperature; atmospheric concentrations of carbon dioxide; gross world product; external debt of developing countries; world production of paper, roundwood, gold, bicycles, cars, pesticides, and cigarettes; population growth; and cases of HIV/AIDS. All of these vital signs continued their 30- and 40-year trends within an expected range of up and down fluctuations. The three remaining vital signs that showed a break in 40-year trends were world carryover grain stocks, which peaked in 1987; world fertilizer use, which peaked in 1989; and coal use, which peaked in 1988-89.

Thus several significant changes occurred in 1987-88 indicating a turn toward God, increased altruism (in the United States), and vigorous new efforts to wage peace and to stop the depletion of the ozone layer. The confluence of these trends shows predicted changes at the predicted critical years. NDErs also predicted that these changes would reduce disasters.

\section{Is There Evidence for the New Age Effect?}

The trend data on international disasers are presented in the next four graphs. Figure 9 shows a steep rise in the worldwide number 


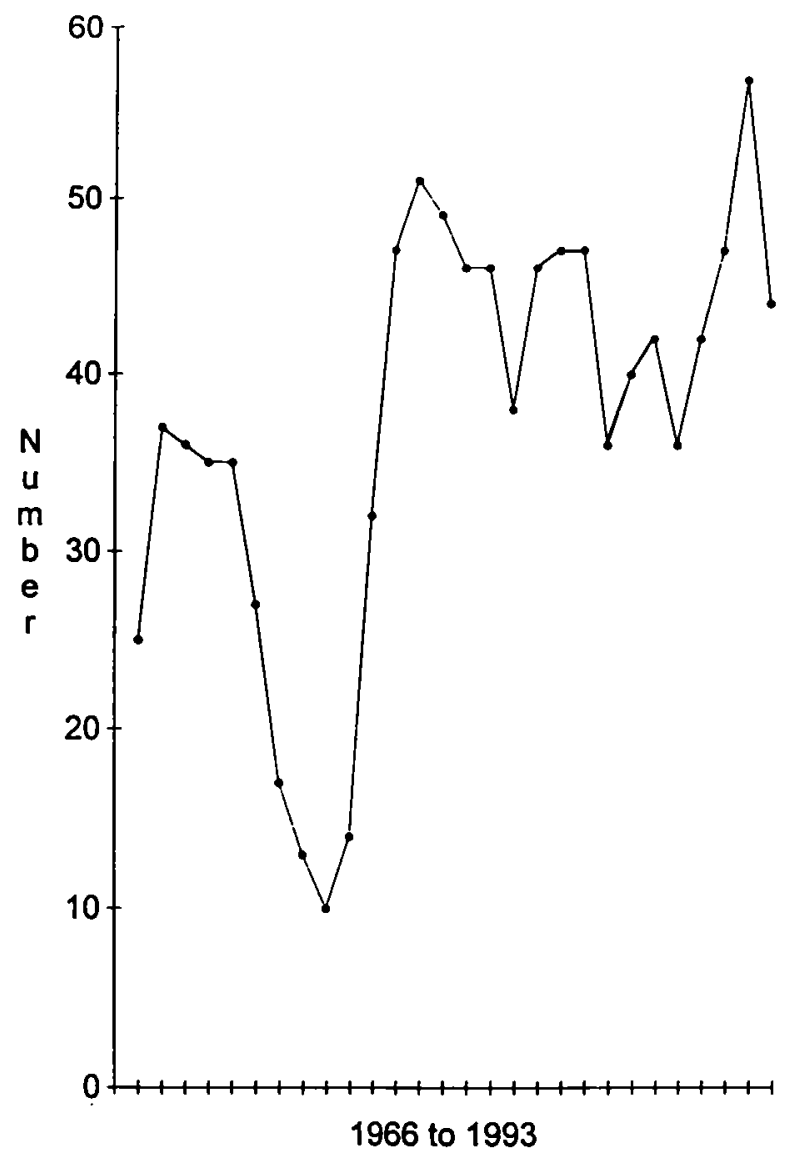

Figure 9. Worldwide trends in earthquakes and volcanos, 1966-93 (rolling three-year totals). Source: U.S. Office of Foreign Disaster Assistance.

of earthquakes and volcanos beginning in 1975. A peak occurred in 1978, 10 years before the predicted critical year, and then drifted lower for 11 years before another rise began in 1990. From a larger perspective, it appears that there has been a steady rise in the number of earthquakes and volcanos, within a fairly constant range in yearly variations. Thus the data on earthquakes and volcanos do not support the New Age Effect. 


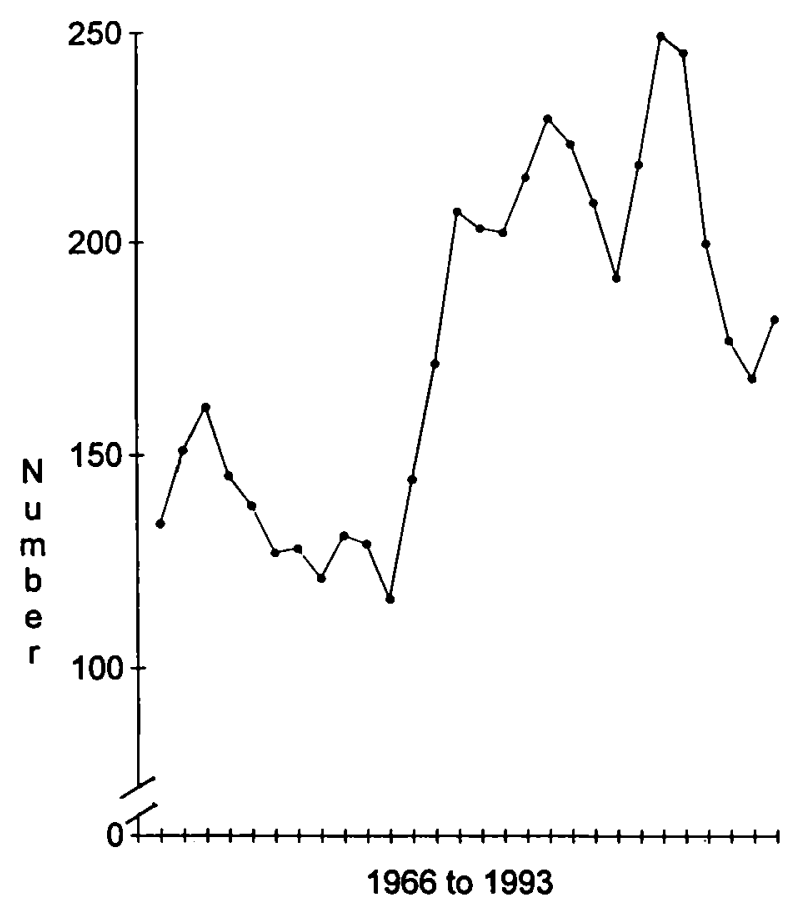

Figure 10. Worldwide trends in killer weather, 1966-93 (rolling three-year totals). Source: U.S. Office of Foreign Disaster Assistance.

As shown in Figure 10, international killer weather dramatically increased beginning in 1977 and peaked in 1988, the year predicted in PVs. These data tend to support the New Age Effect.

Two additional kinds of disaster were not mentioned by either Kenneth Ring (1982, 1985, 1988) or Margot Grey (1985): fires and accidents. These disasters may not have been seen in the PVs, or may not have been mentioned to Ring and Grey. Figure 11 shows that disastrous inernational fires began to rise in 1976 and started to decline in 1987. These data also support the New Age Effect. Figure 12 shows that the rise in international accidents peaked in the predicted year and then began to decline. The form of the trend and the predicted peak year support the PV predictions. 


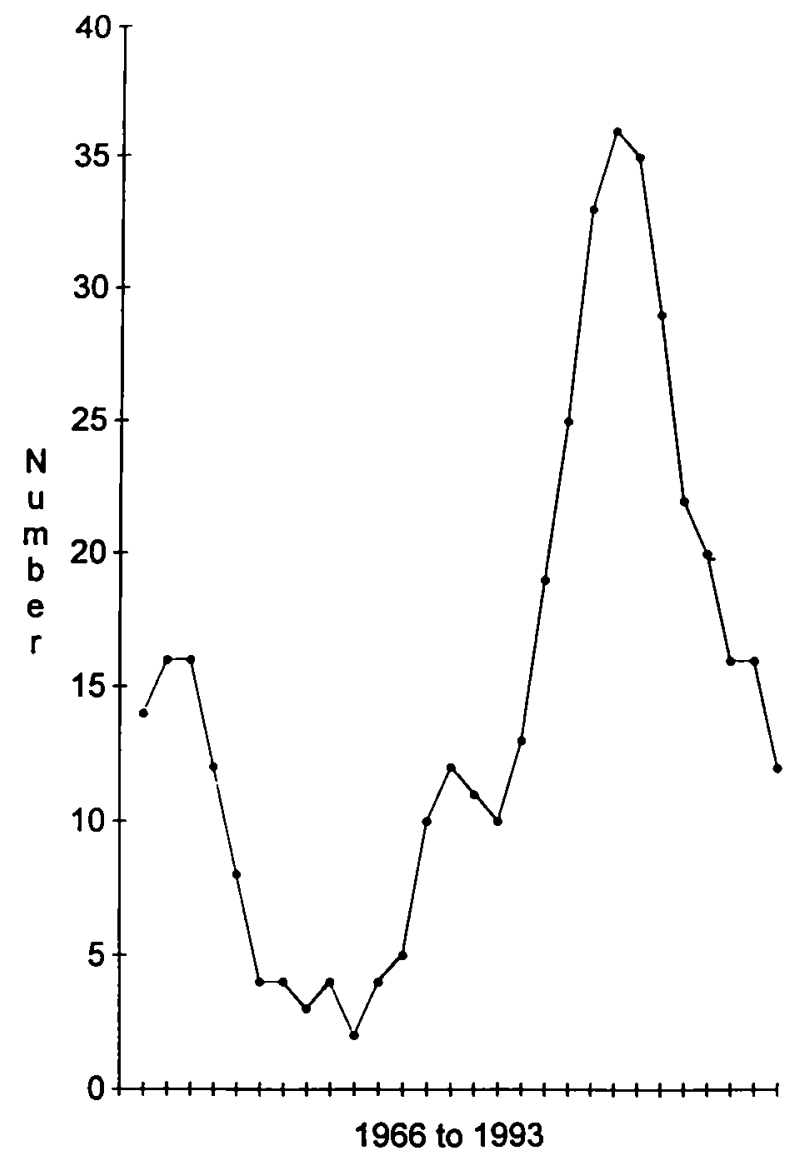

Figure 11. Worldwide trends in disastrous fires, 1966-93 (rolling three-year totals). Source: U.S. Office of Foreign Disaster Assistance.

\section{Discussion}

Theoretically, trends can take many shapes: flat, random, sawtoothed, rising, falling, bimodal, and so on. It seems uncanny that 15 of the 17 trends examined above took the predicted form. Of all the possible years to hit highs or lows, it is doubly uncanny that these peaks occurred when predicted, and that disasters were correlated with trends in caring, as predicted. While I found data supporting 


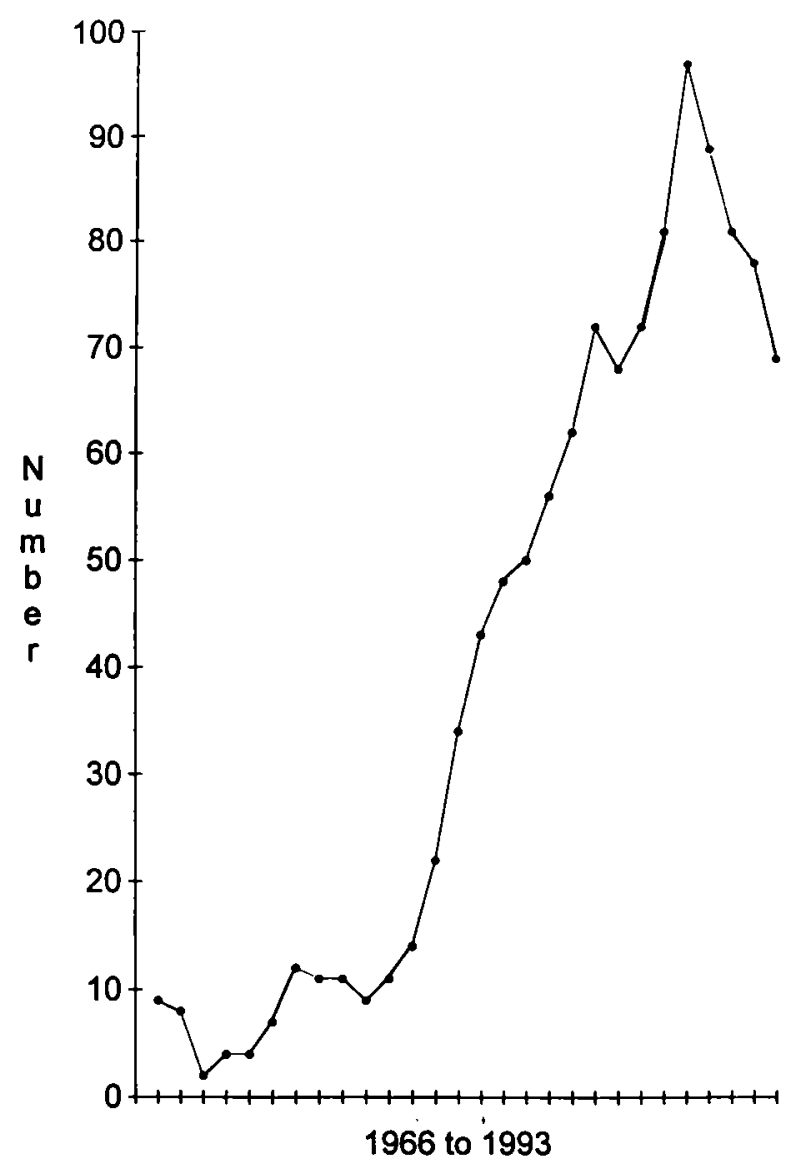

Figure 12. Worldwide trends in disastrous accidents, 1966-93 (rolling three-year totals). Source: U.S. Office of Foreign Diaster Assistance.

the hypothesized New Age Effect in every area where I looked, several critiques and alternative hypotheses should be examined.

\section{Weakness of the Data}

Most of the PV predictions were false: there was no pole shift, massive geological change, socioeconomic chaos, or nuclear war. The 
observed peaks in fires and accidents were not predicted. There are no reliable data on United States disaster trends, which PVs did predict, and no data on global changes in religiosity or caring for others. At most, what remains is a chauvinistic view that American consciousness controls the fate of the world.

But while the apocalyptic predictions did not come to pass, the New Age Effect was predicted to modify the disastrous outcomes. Trends in three measures of caring and worldwide disasters broke in the critical period of 1987-88. The inclusion of unpredicted areas (accidents and fires) strengthens the hypothesis by showing that the New Age Effect generalized to other areas not mentioned in PVs.

On the other hand, partial disconfirmations are not sufficient to justify discarding the majority of supporting data. Science builds on imperfect, probabilistic data to create progressively more adequate theories that allow increasingly accurate descriptions, predictions, and control.

On the other hand, just as reality is more complex than our theories, the evolution of the planet is more complicated than portrayed in the PVs. PVs may be seen as allegories to teach a moral lesson, the McGuffy Readers of visionaries. The plot is simplified and exaggerated to clarify the message. Events are created to dramatize basic truths and to inspire readers to change.

One of the truths in the PVs appears to be the hypothesis that the quality of our consciousness and actions is causally linked to the rate of worldwide disasters. In spite of imperfect data and PVs that are somewhat veiled, there are strong negative correlations between measures of religiosity, caring for others and the planet, and several types of disasters.

\section{Coincidence or Magical Thinking}

Calling these correlations "coincidence" assumes there is no explanation to be found, thus effectively stopping theorizing and research. That is a decidedly anti-intellectual position. Calling these correlations "magical" comes from an overly simplistic notion of causality as a single line of links in a chain. Modern field theories open several alternative explanations. The probability of so many "coincidences" is extremely remote. It is easier to believe the New Age Effect than to believe in coincidence. 


\section{"Super ESP"}

Changing the name of this phenomenon from PVs to "super ESP" does not advance understanding, prediction, or control. "Super ESP" implies transcendence of time, space, causality, and the limits of our senses, just as PVs do. Both explanations challenge current scientific paradigms, and both raise the possibility of the survival of consciousness beyond physical death.

\section{Unconscious Projection of Existing Trends into the Future}

The rise in worldwide killer weather began before 1980. NDErs, who must have been aware of this, may simply have extended the trend in the form of a lucid, archetypical dream.

If NDErs were aware of planetary trends, however, why were they wrong in their predictions about increased earthquakes and volcanos, and why were they not aware of the increase in accidents and fires? The "unconscious awareness" hypothesis does not explain predictions of the critical years for a turning point, nor the predicted correlations between disaster and religiosity trends.

Disasters Naturally Teach Humility, Interdependence, and Religiosity

The trend data showed that measures of caring increased after increases in killer weather, fires, and accidents. It is true that altruism and heroism, not looting and rioting, are the dominant reactons to disasters. Government responses to disasters inevitably are delayed. In the interim, local resources are donated to relieve suffering and save lives. Private voluntary organizations often provide more and faster aid than do governments.

These typical consequences change attitudes and relationships away from selfish interests and toward the welfare of others, away from the boundaries of caste and class and toward cooperation for mutual benefit, away from faith in national politics and toward local cooperation and international interdependence. The causal relationship between disasters and caring is understandable without resorting to mysterious effects (Cornell, 1982; Raphael, 1986). 
This natural response to disasters could explain these correlations if caring rose with increasing disasters. It did not; caring continued to rise as disasters decreased. Nor can this hypothesis explain how NDErs who had PVs selected the critical years for trends to break.

\section{The So-called New Age Effect Is Not New}

In fact, the New Age Effect is ancient and continuous. In the Torah, disasters were a punishment for turning away from God (for example, the Flood and the destruction of Sodom and Gomorrah) and an inducement to do the right thing (for example, the 10 disasters sent to change Pharaoh's decision and free the Jews). Warnings of "repent or suffer" were made by Amos, Isaiah, Jeremiah, Malachi, Micah, and Saul. John's revelation predicted a New Age after painful lessons were to be learned from Armageddon, the apocalypse, and a false prophet. This archetypical prophesy has been repeated by founders of religions, Nostradamus, Edgar Cayce, and recent channelers, often focused on the year 2,000 (Noorbergen, 1984).

The term New Age Effect was not meant to denote the trendy, recent "New Age" music, books, and workships. It denotes the ancient claim that levels of collective consciousness are causally related to disaster rates, that godlessness, greed, and sins against the planet cause catastrophes, and that turning to God, waging peace, and promoting altruism will usher in the New Age. The ancient idea of the New Age Effect challenges modern paradigms. For serious scientists, prophesies are the frozen yogurt of futurism.

\section{Conclusion}

Do the remarkable correlations of predicted peaks and troughs in trend data prove that consciousness survives death and enters a realm where cosmic history and the future can be known? Do they prove the apocalypse inevitable, as portrayed in the PVs, and only delayed? Can the apocalypse be avoided by greater godliness, generosity, and stweardship of the earth? Does love ultimately rule the world? These questions urge further tests of the New Age Effect.

Such tests are possible. First, global data on other predictors can be gathered, for example, changes in international foreign aid, religious fundamentalism, and destruction of old forests. Second, it is pos- 
sible to study the New Age Effect at the national, state, and even college campus level. Carefully controlled studies have shown that Sidhi meditation by as few as one hundredth of one percent of the population of a city or nation is related to reduced crime rates, motor vehicle fatality rates, homicide and suicide rates, fetal mortality rates, hospital admission rates, and fires. The meditation period was compared with the same length of time before and after, with rates during comparable dates in previous years, and with other cities and states (Dillbeck, Banus, Polanzi, and Landrith, 1988; Dillbeck, Cavanaugh, Glenn, Orme-Johnson, and Mittlefield, 1987; Dillbeck, Landrith, and Orme-Johnson, 1981; Orme-Johnson, Gelderloos, and Dillbeck, 1988). Local predictors might include religiosity, altruism, and environmental protection policies.

At present there are sufficient data supporting the New Age Effect to take it seriously, and there is room for doubt. Neither scientific predictions or mystic prophesies ever are 100 percent accurate. Thus, even after further research, we will remain where we have been, on our own to choose a response to each new prediction, and through our responses, inescapably, to create the future.

\section{References}

Astin, A. W., Korn, W. S., and Riggs, E. R. (1993). Women's aspirations reach record highs. In The American freshman: National norms for fall, 1993 (p. 2). Los Angeles, CA: Higher Education Research Institute, Graduate School of Education. UCLA.

Audette, J. (1981). Visions of knowledge in NDEs. Vital Signs, 1(4), 5-6.

Brown, L. R. (1994). Vital signs: The trends that are shaping our future. New York, NY: Norton.

Brown, L. R., et. al. (1994). State of the world: A Worldwatch Institute report on progress toward a sustainable society. New York, NY: Norton.

Cornell, J. (1982). The great international disaster book. New York, NY: Scribner's.

Dey, E. L., Astin, A. W., Korn, W. S., and Riggs, E. R. (1992). Increased freshman interest in racial understanding and social change. In The American freshman: $\mathrm{Na}$ tional norms for fall, 1992. (pp. 1-2). Los Angeles, CA: Higher Education Research Institute, Graduate School of Education, UCLA.

Dillbeck, M. C., Banus, C. B., Polanzi, C., and Landrith, C. S. (1988). Test of a field model of consciousness and social change: The Transcendental Mediation and TMSidhi program and decreased urban crime. Journal of Mind and Behavior, 9, 457 485.

Dillbeck, M. C., Cavanaugh, K. L., Glenn, T., Orme-Johnson, D. W., and Mittlefield, V. (1987). Consciousness as a field: The Transcendental Meditation and TM-Sidhi program and changes in social indicators. Journal of Mind and Behavior, 8, 67-104.

Dillbeck, M. C., Landrith, G., and Orme-Johnson, D. W. (1981). The Transcendental Meditation program and crime rate change in a sample of forty-eight cities. Journal of Crime and Justice, 4, 25-45. 
Gallup Poll News Service. (1994). Religious trends. Princeton, NJ: Gallup Organization.

Grey, M. (1985). Return from death: An exploration of the near-death experience. London, England: Arkana.

Noorbergen, R. (1984). A.D. 2000: A book about the end of time. Indianapolis, IN: Bobbs-Merrill.

Norris, R. S., and Arkin, W. A. (1993). Nuclear notebook: Estimated nuclear stockpiles 1945-1993. Bulletin of the Atomic Scientists, 49(10), 57.

Orme-Johnson, D. W., Gelderloos, P., and Dillbeck, M. C. (1988). The effects of the Maharishi Technology of the United Field on the US quality of life (1964-1984). Social Sciences Perspectives Journal, 2, 127-146.

Raphael, B. (1986). When disaster strikes: How individuals and communities cope with catastrophe. New York, NY: Basic Books.

Ring, K. (1982). Precognitive and prophetic visions in near-death experiences. Anabiosis: The Journal of Near-Death Studies, 2, 47-74.

Ring, K. (1984). Heading toward omega: In search of the meaning of the near-death experience. New York: Morrow.

Ring, K (1988). Prophetic visions in 1988: A critical reappraisal. Journal of NearDeath Studies, 7, 4-18. 